\title{
Utilization of Xylan-rich Steam Explosion Liquid from Processing of Poplar for Hydrogel Synthesis
}

\author{
Huimei Wang, Zhong Liu,* Lanfeng Hui,* Lan Ma, Xiaodi Wang, and Bianzhi Zhang \\ A high-performance hydrogel was successfully fabricated using xylan-rich \\ concentrated steam explosion liquid (CSEL). The method used was a free- \\ radical graft copolymerization of acrylic acid (AA) and acrylamide (AM) \\ onto a primarily xylan backbone in CSEL, with a redox system of \\ ammonium persulfate/anhydrous sodium sulfite as the indicator and $N, N$ - \\ methylenebisacrylamide (MBA) as the cross-linker. The effects of \\ independent parameters (the dosages of the indicator, $A M, A A$, and the \\ cross-linker) on the swelling ratio of the as-prepared hydrogel were studied \\ via an optimal design of the response surface methodology (RSM). Under \\ the optimal conditions ( $80.9 \mathrm{mg}$ of initiator, $349.6 \mathrm{mg}$ of AM, $988.7 \mathrm{mg}$ of \\ $\mathrm{AA}$, and $9.39 \mathrm{mg}$ of cross-linker), the swelling ratio of the prepared \\ hydrogel (Xyl-AM-co-AA) was $276.6 \mathrm{~g} / \mathrm{g}$, which was close to the predicted \\ value $(255.7 \mathrm{~g})$. The swelling behaviors of Xyl-AM-co-AA at different \\ temperatures and $\mathrm{pH}$ values were also analyzed. The results showed that \\ the swelling ratios varied at different temperatures and $\mathrm{pH}$ values, implying \\ their potential use as smart materials. Analysis by Fourier transform \\ infrared spectroscopy and scanning electron microscopy confirmed the \\ cross-linked and hygroscopic behavior of Xyl-AM-co-AA.
}

Keywords: Hemicellulose; Steam explosion liquid; Hydrogels; Swelling ratio

Contact information: Tianjin Key Laboratory of Pulp \& Paper, Tianjin University of Science and Technology, Tianjin 300457, China; *Corresponding authors: mglz@tust.edu.cn; huipeak@163.com

\section{INTRODUCTION}

Hydrogels are polymers structured by hydrophilic networks formed by chemical or physical cross-linking. They swell in water or aqueous solutions without dissolving (Yang et al. 2011; Ahmed 2015). With many hydrophilic functional groups, such as hydroxyl, carboxylic acid, and amines, on the main chain of polymers, hydrogels can have excellent liquid adsorption ability (Wang et al. 2017; Liu et al. 2019). At the same time, the formation of cross-links between polymer chains often results in their insolubility (Ahmed 2015; Liu et al. 2019).

In recent years, the use of environmentally sensitive hydrogels as intelligent material has attracted considerable attention. Environmentally sensitive hydrogels are also called intelligent hydrogels (Yashin and Balazs 2006), and demonstrate response to environmental stimuli, such as temperature, $\mathrm{pH}$, salt, and biomolecules (Peng et al. 2011; Dai et al. 2016). Their response behavior is mainly reflected in the changes in volume size and pore size of the hydrogel (Qiu and Park 2001). Of multiple environmentally sensitive hydrogels, temperature- and $\mathrm{pH}$-sensitive hydrogels have attracted much attention by researchers in the biomedical field, especially in controlled drug delivery systems and immobilized enzyme systems (Qiu and Park 2001; Zhang et al. 2004; Kipcak et al. 2014). Risbud et al. (2000) synthesized a pH-sensitive hydrogel by cross-linking chitosan and 
polyvinyl pyrrolidone with glutaraldehyde, and the result implied that the hydrogel could be a potential candidate for antibiotic delivery in an acidic environment.

Generally, hydrogels can be synthesized by various approaches, such as radicalinduced copolymerization, frontal copolymerization, graft copolymerization, crosslinking, and ionizing radiation from synthetic polymers or polysaccharides (Marandi et al. 2008). However, most of the synthetic polymers are petroleum-based, making the products unsustainable (Al-Rudainy et al. 2019). Therefore, many natural materials, such as biomass polysaccharides and inorganic clay minerals, have been developed as raw materials to realize low-cost, renewable, non-toxic, and biodegradable hydrogel production (Bao et al. 2011; Kabiri et al. 2011).

Hemicelluloses are the second most abundant polysaccharides in nature after cellulose, constituting over $20 \%$ of the cell walls in wood (Al-Rudainy et al. 2019). Considering the abundance of hydrophilic functional groups on hemicellulose backbones, hemicellulose could be a promising feedstock to produce hydrogels ( $\mathrm{Li}$ and Pan 2010; Zhao et al. 2014). Recently, researchers have shown great interest in hemicellulose-based hydrogels, especially environment-sensitive hydrogels with light-responsive abilities. Peng et al. (2011) synthesized an intelligent hemicelluloses-graft-acrylic acid ionic hydrogel with $N, N^{`}$-methylenebisacrylamide (MBA) as a cross-linker. Expansion of the network occurred at high $\mathrm{pH}$, whereas shrinkage appeared at low $\mathrm{pH}$, in salt solutions, and in organic solvents. Cao et al. (2014) prepared hemicellulose-based hydrogels by free radical copolymerization, which showed multiple response behaviors to $\mathrm{pH}$, water/ethanol alternating solutions, and light.

However, in the cell walls of biomass, hemicellulose is closely linked with cellulose and lignin by intermolecular hydrogen bonds and covalent bonds, respectively, resulting in increasing the difficulty of hemicellulose separation, thus limiting the utilization of hemicellulose. Therefore, the efficient utilization of hemicellulose to extract hemicellulose by appropriate separation methods is highly important.

Steam explosion is a high-efficiency method used to separate hemicellulose (Ruiz et al. 2008). After steam explosion treatment, hemicellulose-based polysaccharides, mainly xylan-based polysaccharides (Xyl-P), are separated from biomass and dissolved in the steam explosion liquid. In this study, the concentrated steam explosion liquid (CSEL) of poplar was employed as the raw material to graft copolymerize with acrylic acid (AA) and acrylamide (AM) to prepare xylan-based hydrogels. By incorporating AA and AM into the network, hydrogels can have excellent water absorption ability. To explore the optimal preparation conditions of hydrogels, the response surface methodology (RSM) method was adopted. Then, the water swelling ratios of the prepared hydrogel in different $\mathrm{pH}$ and temperature were measured. The morphology and chemical properties were investigated by scanning electron microscopy (SEM) and Fourier transform infrared spectroscopy (FTIR).

\section{EXPERIMENTAL}

\section{Materials}

Poplar chips were provided by Sun Paper Co., Ltd. (Shandong, China), with an average size of $30 \times 30 \times 5 \mathrm{~mm}^{3}$. Acrylic acid $(99.5 \%)$, acrylamide $(99.0 \%)$, and $N, N^{\prime}-$ methylenebisacrylamide (98.0\%) were purchased from Sinopharm Chemical Reagent Co., Ltd. (Shanghai, China). NaOH was supplied by Aladdin Reagent Co., Ltd. (Shanghai, 
China), and ammonium persulfate (99.0\%) and anhydrous sodium sulfite (98.0\%) were purchased from Tianjin Damao Chemical Reagent Company (Tianjin, China). All the reagents were used without further purification.

\section{Methods}

Preparation of the steam explosion liquid

Steam explosion pretreatment was conducted in an explosion device comprised of a 5- $\mathrm{L}$ reaction chamber, a steam generator, and a sample collector. After $0.4 \mathrm{~kg}$ of poplar chips (dry base) were loaded into the reaction chamber, high-pressure steam was introduced to reach the temperature of $209{ }^{\circ} \mathrm{C}$, during a processing time of $7 \mathrm{~min}$. After steam-explosion pretreatment, the hemicellulose-rich liquid was separated from the solids. With a rotary evaporator, the CSEL was obtained. The components' contents of CSEL were also determined by high-performance liquid chromatography (HPLC) according to NREL protocol (Sluiter et al. 2006).

\section{Preparation of hydrogels}

A total of $5 \mathrm{~mL}$ of CSEL was added in a beaker as raw material. After simmering the $\mathrm{N}_{2}$ for 20 min to discharge oxygen, a certain amount of indicator (redox system of ammonium persulfate and anhydrous sodium sulfite) was dissolved in the CSEL, and the mixture was placed on a magnetic stirrer for magnetic stirring at $60{ }^{\circ} \mathrm{C}$ for $15 \mathrm{~min}$ to generate free radicals. Subsequently, AM and AA were added in succession at $60{ }^{\circ} \mathrm{C}$ and stirred for $15 \mathrm{~min}$. Subsequently, a certain amount of MBA was added to the beaker as the cross-linker. Finally, the mixture was placed at $25^{\circ} \mathrm{C}$ for $12 \mathrm{~h}$ to mold. After the reaction, the as-synthesized hydrogels were washed with $2 \mathrm{~mol} / \mathrm{L} \mathrm{NaOH}$ and distilled water.

\section{Experimental design for preparing hydrogels}

The experimental procedure for preparing hydrogels was designed with the RSM method. This method was adopted for optimizing the swelling ratio of hydrogels. In this study, the RSM method was used to evaluate the relationship among four experimental variables (dosages of initiator $\left[\mathrm{X}_{1}\right], \mathrm{AA}\left[\mathrm{X}_{2}\right], \mathrm{AM}\left[\mathrm{X}_{3}\right]$, and MBA $\left[\mathrm{X}_{4}\right]$ ) and the swelling ratio of hydrogels, as well as to obtain the optimal hydrogel with the highest swelling ratio. A Box-Behnken design with four factors at three levels was considered. The range of these four independent variables $\left(\mathrm{X}_{1}, \mathrm{X}_{2}, \mathrm{X}_{3}\right.$, and $\left.\mathrm{X}_{4}\right)$ and the center point values are presented in Table 1. The statistical software Design-Expert (Version 8.0.5; Stat-Ease Co., Ltd., Minneapolis, America) was used to analyze the regression analysis of the experimental data and the response surface plots. The mathematical model for the swelling ratio of hydrogel was fitted to the second-order polynomial model, as in Eq. 1,

$$
\begin{aligned}
& Y=\beta_{0}+\beta_{1} X_{1}+\beta_{2} X_{2}+\beta_{3} X_{3}+\beta_{4} X_{4}+\beta_{11} X_{1}^{2}+\beta_{22} X_{2}^{2}+\beta_{33} X_{3}^{2}+\beta_{44} X_{4}^{2}+\beta_{12} X_{1} X_{2}+ \\
& \beta_{13} X_{1} X_{3}+\beta_{14} X_{1} X_{4}+\beta_{23} X_{2} X_{3}+\beta_{24} X_{2} X_{4}+\beta_{34} X_{3} X_{4}
\end{aligned}
$$

where $Y$ is the swelling ratio of the hydrogel; $X_{1}, X_{2}, X_{3}$, and $X_{4}$ are the independent variables; $\beta_{0}$ is the regression coefficient; $\beta_{1}, \beta_{2}, \beta_{3}$, and $\beta_{4}$ are the linear coefficients; $\beta_{11}$, $\beta_{22}, \beta_{33}$, and $\beta_{44}$ are the quadratic coefficients; $\beta_{12}, \beta_{13}, \beta_{14}, \beta_{23}, \beta_{24}$, and $\beta_{34}$ are the secondorder interaction coefficients. 
Table 1. Experimental Range and Levels for the Independent Variables

\begin{tabular}{|c|c|c|c|c|}
\hline \multirow{2}{*}{ Independent Variables } & \multirow{2}{*}{ Symbol } & \multicolumn{3}{|c|}{ Range and Level } \\
\cline { 3 - 5 } & & -1 & 0 & 1 \\
\hline Dosage of initiator $(\mathrm{mg})$ & $X_{1}$ & 50 & 70 & 90 \\
\hline Dosage of AA $(\mathrm{mg})$ & $X_{2}$ & 150 & 250 & 350 \\
\hline Dosage of AM (mg) & $X_{3}$ & 500 & 750 & 1000 \\
\hline Dosage of MBA $(\mathrm{mg})$ & $X_{4}$ & 9 & 12.5 & 16 \\
\hline
\end{tabular}

Characterization of the hydrogels

The surface morphology of freeze-dried hydrogels swelled at different swelling conditions were analyzed using a scanning electron microscope (JSM-6400; JEOL Co., Ltd., Tokyo, Japan). Prior to the observation, the hydrogel surfaces were coated with platinum (SB1361; Jieou Road Science and Trade Co., Ltd, Beijing, China) to render them electrically conducive. The FTIR spectra of the prepared hydrogel and dried CSEL were recorded on VERTEX 70 Fourier transform spectrometer (Bruker Optics, Karlsruhe, Germany) with a wavelength range of 4000 to $400 \mathrm{~cm}^{-1}$, using the $\mathrm{KBr}$ disk method with a mass ratio of sample to $\mathrm{KBr} 1: 100$.

\section{Swelling degree of hydrogels}

The gravimetric method was adopted to analyze the swelling ratio of the prepared hydrogels. The swelling ratios of the dehydrated hydrogel samples were measured at 25 ${ }^{\circ} \mathrm{C}$. When the samples reached the equilibrium swelling state, the swollen hydrogels were removed from the water and immediately weighed after wiping off the excess water on their surfaces.

To explore the response behaviors of prepared hydrogels to $\mathrm{pH}$ and temperature, the dehydrated hydrogel samples were immersed in $40 \mathrm{~mL}$ of aqueous solutions with $\mathrm{pH}$ levels from 2 to 11 and immersed in distilled water at temperatures ranging from $5{ }^{\circ} \mathrm{C}$ to $45^{\circ} \mathrm{C}$, respectively. The swelling ratio $(S R)$ and equilibrium swelling ratio $\left(S_{\text {eq }}\right)$ were calculated by Eqs. 2 and 3, respectively (Sun et al. 2013),

$$
\begin{aligned}
& S R=\left(W_{\mathrm{t}}-W_{\mathrm{o}}\right) / W_{\mathrm{o}} \\
& S_{\mathrm{eq}}=\left(W_{\mathrm{t}}-W_{\mathrm{o}}\right) / W_{\mathrm{o}}
\end{aligned}
$$

where $W_{0}, W_{\mathrm{t}}$, and $W_{\text {eq }}$ are the weights (g) of dried hydrogels, swollen hydrogels at the time $t$, and swollen hydrogels at equilibrium swelling state, respectively.

\section{RESULTS AND DISCUSSION}

\section{Component Analysis of CSEL}

Table 2 shows the components' contents of CSEL. As shown in Table 2, the main components of the steam expansion liquid were glucose-based polysaccharide (Glu-P), xylose-based polysaccharide (Xyl-P), arabinose-based polysaccharide (Arab-P), formic acid, and acetic acid. The Xyl-P content was the highest in steam expansion liquid, at 37.7 $\mathrm{mg} / \mathrm{mL}$. 
Table 2. Component Concentrations of Concentrated Steam Explosion Liquid

\begin{tabular}{|c|c|c|c|c|c|}
\hline Components & Glu-P & Xyl-P & Arab-P & $\begin{array}{c}\text { Formic } \\
\text { Acid }\end{array}$ & $\begin{array}{c}\text { Acetic } \\
\text { Acid }\end{array}$ \\
\hline Concentration $(\mathrm{mg} / \mathrm{mL})$ & 6.4 & 37.7 & 1.5 & 2.7 & 10.8 \\
\hline
\end{tabular}

\section{RSM Study for Preparing Hydrogels}

Model analysis

A quadratic model was recommended to evaluate the responses as functions of independent variables and their interactions. According to Box-Behnken design, 29 groups of experiments were conducted to prepare hydrogels from CSEL; Table 3 shows the combinations of the preparation conditions. Based on the results, the following regression equation was obtained to describe the swelling ratio from the experimental responses,

$$
\begin{aligned}
& Y=205.36-16.56 X_{1}+1.69 X_{2}+8.34 X_{3}-18.44 X_{4}+18.75 X_{1} X_{2}+27.17 X_{1} X_{3}+ \\
& 5.60 X_{1} X_{4}-0.48 X_{2} X_{3}-16.90 X_{2} X_{4}-26.27 X_{3} X_{4}-20.74 X_{1}^{2}-1.99 X_{2}^{2}-9.81 X_{3}^{2}- \\
& 22.74 X_{4}{ }^{2}
\end{aligned}
$$

where $Y$ is the swelling ratio of hydrogel; and $X_{1}, X_{2}, X_{3}$, and $X_{4}$ are the independent variables of dosages of the initiator, AM, AA, or MBA, respectively.

Table 3. Independent Variables of the Central Composite Design and the Results of Response Surface Analysis

\begin{tabular}{|c|c|c|c|c|c|}
\hline Run & $X_{1}(\mathrm{mg})$ & $X_{2}(\mathrm{mg})$ & $X_{3}(\mathrm{mg})$ & $X_{4}(\mathrm{mg})$ & $Y(\mathrm{~g} / \mathrm{g})$ \\
\hline 1 & 50 & 250 & 500 & 12.5 & 205 \\
\hline 2 & 50 & 250 & 750 & 16 & 156 \\
\hline 3 & 70 & 350 & 1000 & 12.5 & 198 \\
\hline 4 & 70 & 150 & 500 & 12.5 & 184 \\
\hline 5 & 70 & 250 & 750 & 12.5 & 211 \\
\hline 6 & 70 & 250 & 750 & 12.5 & 203 \\
\hline 7 & 90 & 250 & 1000 & 12.5 & 196 \\
\hline 8 & 90 & 250 & 500 & 12.5 & 124 \\
\hline 9 & 70 & 150 & 750 & 9.0 & 172 \\
\hline 10 & 50 & 250 & 750 & 9.0 & 190 \\
\hline 11 & 50 & 350 & 750 & 12.5 & 185 \\
\hline 12 & 70 & 250 & 1000 & 9.0 & 240 \\
\hline 13 & 70 & 350 & 500 & 12.5 & 189 \\
\hline 14 & 90 & 250 & 750 & 9.0 & 142 \\
\hline 15 & 70 & 250 & 1000 & 16.0 & 137 \\
\hline 16 & 70 & 250 & 500 & 16.0 & 166 \\
\hline 17 & 70 & 350 & 750 & 9.0 & 216 \\
\hline 18 & 90 & 150 & 750 & 12.5 & 150 \\
\hline 19 & 70 & 250 & 750 & 12.5 & 203 \\
\hline 20 & 70 & 150 & 1000 & 12.5 & 194 \\
\hline 21 & 50 & 150 & 750 & 12.5 & 227 \\
\hline 22 & 70 & 250 & 750 & 12.5 & 207 \\
\hline 23 & 90 & 250 & 750 & 16.0 & 133 \\
\hline 24 & 70 & 250 & 500 & 9.0 & 174 \\
\hline 25 & 70 & 250 & 750 & 12.5 & 203 \\
\hline 26 & 70 & 350 & 750 & 16.0 & 152 \\
\hline 27 & 90 & 350 & 750 & 12.5 & 184 \\
\hline 28 & 50 & 250 & 1000 & 12.5 & 168 \\
\hline 29 & 70 & 150 & 750 & 16.0 & 176 \\
\hline & & & & & \\
\hline
\end{tabular}


The $\mathrm{R}^{2}$ value for this model was 0.9654 (Fig. 1). This result implied that $96.54 \%$ of the variability in the response could be explained by this model. A comparison between the predicted and observed swelling ratio was also conducted (Fig. 1). It showed that the observed swelling ratio was scattered relatively close to the straight line, thus demonstrating sufficient correlation between the experimental data and the theoretical values. Therefore, the quadratic model was used in this optimization study.

The variance (ANOVA) listed in Table 4 was used to check the F-value to assess the significance and adequacy of the models. As shown in Table 4, the F-value of the swelling ratio was 27.94. Generally, when the $\mathrm{F}$ value is greater than zero, it means that the obtained model is highly feasible, and a higher $\mathrm{F}$ value results in a more significant feasibility (Pourjavadi et al. 2004; Dil et al. 2016). The significance of each coefficient and the pattern of interactions between the factors were determined by the p-value (Prob $>F)$. The $\mathrm{p}$-value indicates the possibility of obtaining corresponding F-value due to error interference. As listed in Table 4, the p-value for the swelling ratio was $<0.0001$, indicating that the model had statistical significance. The non-significant "lack-of-fit" was used to express the predictability of the model. In this experiment, the "lack-of-fit" value was $0.0600>0.05$, which showed the low contribution compared with pure error (Asfaram et al. 2016). Moreover, the coefficient of variation (CV \%) was $4.12 \%$, less than $10 \%$, further indicating that the fitting degree of the model was better. From the above, this model can be used for preliminary analysis and prediction in the preparation process of hydrogels.

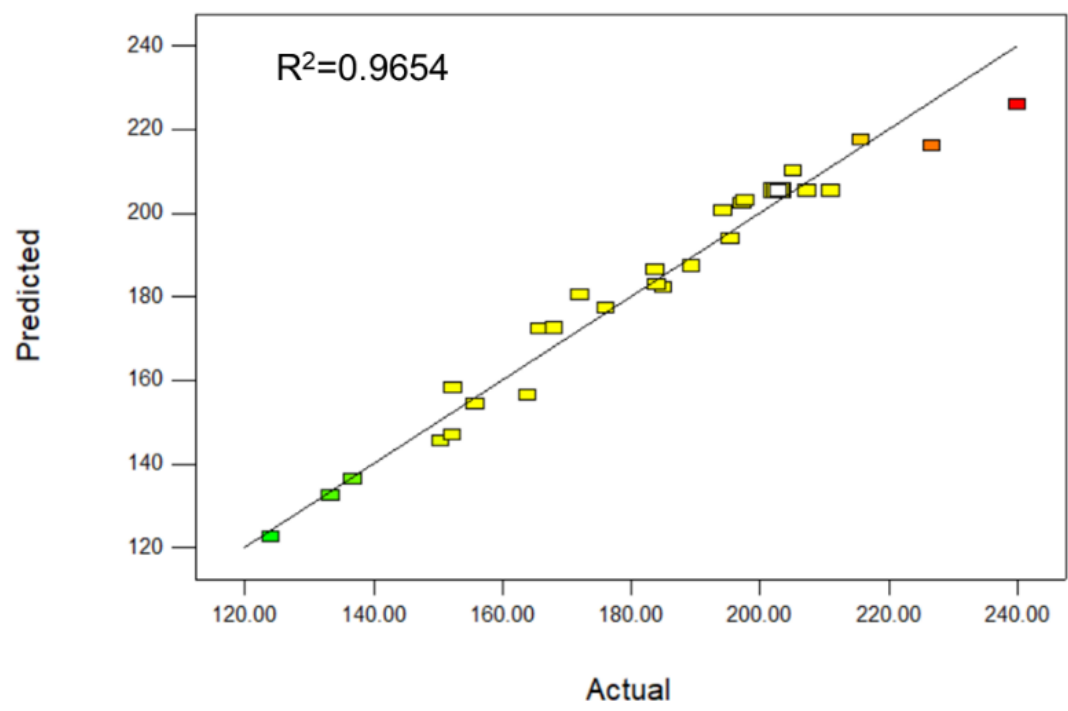

Fig. 1. The actual coefficient of determination and the predicted coefficient of determination versus the observed swelling ratio 
Table 4. Analysis of Variance (ANOVA) for Swelling Ratio

\begin{tabular}{|c|c|c|c|c|c|c|}
\hline $\begin{array}{c}\text { Sources of } \\
\text { Variation }\end{array}$ & $\begin{array}{c}\text { Sum of } \\
\text { Squares }\end{array}$ & DF & Mean Square & F value & Prob $>$ F & State \\
\hline Model & 22059.68 & 14 & 1575.69 & 27.94 & $<0.0001$ & Significant \\
\hline$X_{1}$ & 3290.14 & 1 & 3290.14 & 58.35 & $<0.0001$ & - \\
\hline$X_{2}$ & 34.34 & 1 & 34.34 & 0.61 & 0.4482 & - \\
\hline$X_{3}$ & 835.00 & 1 & 835.00 & 14.81 & 0.0018 & - \\
\hline$X_{4}$ & 4081.14 & 1 & 4081.14 & 72.37 & $<0.0001$ & - \\
\hline$X_{1} X_{2}$ & 1406.15 & 1 & 1406.15 & 24.94 & 0.0002 & - \\
\hline$X_{1} X_{3}$ & 2953.92 & 1 & 2953.92 & 52.38 & $<0.0001$ & - \\
\hline$X_{1} X_{4}$ & 125.44 & 1 & 125.44 & 2.22 & 0.1580 & - \\
\hline$X_{2} X_{3}$ & 0.90 & 1 & 0.90 & 0.026 & 0.9011 & - \\
\hline$X_{2} X_{4}$ & 1142.44 & 1 & 1142.44 & 20.26 & 0.0005 & - \\
\hline$X_{3} X_{4}$ & 2761.50 & 1 & 2761.50 & 48.97 & $<0.0001$ & - \\
\hline$X_{1}{ }^{2}$ & 2789.10 & 1 & 2789.10 & 49.47 & $<0.0001$ & - \\
\hline$X_{2}{ }^{2}$ & 25.64 & 1 & 25.64 & 0.45 & 0.5111 & - \\
\hline$X_{3}{ }^{2}$ & 624.66 & 1 & 624.66 & 11.08 & 0.0050 & - \\
\hline$X_{4}{ }^{2}$ & 3353.72 & 1 & 3353.72 & 59.47 & $<0.0001$ & - \\
\hline Residual & 789.46 & 14 & 56.39 & - & - & - \\
\hline Lack of Fit & 734.65 & 10 & 73.46 & 5.36 & 0.0600 & Not significant \\
\hline Pure Error & 54.81 & 4 & 13.70 & - & - & - \\
\hline Total & 22849.13 & 28 & - & - & - & - \\
\hline
\end{tabular}

\section{Effect of variables on the response}

The 3D response surface plots are presented in Fig. 2, which depicts the effects of the dosages of the respective initiator, AM, AA, or MBA, on swelling ratio. As shown in Fig. 2a, the swelling ratio of hydrogel increased with increased initiator dosage, reached the maximum, and then decreased. The main reason for the final decrease may have been that less quantity of initiator led to less production of free radicals, thereby resulting in lower grafting rates of AA and AM. When the amount of initiator was too high, the excess initiator caused the free radical termination reaction. This reaction reduced the grafting rates of $\mathrm{AA}$ and $\mathrm{AM}$ and the swelling ratio of hydrogel. 

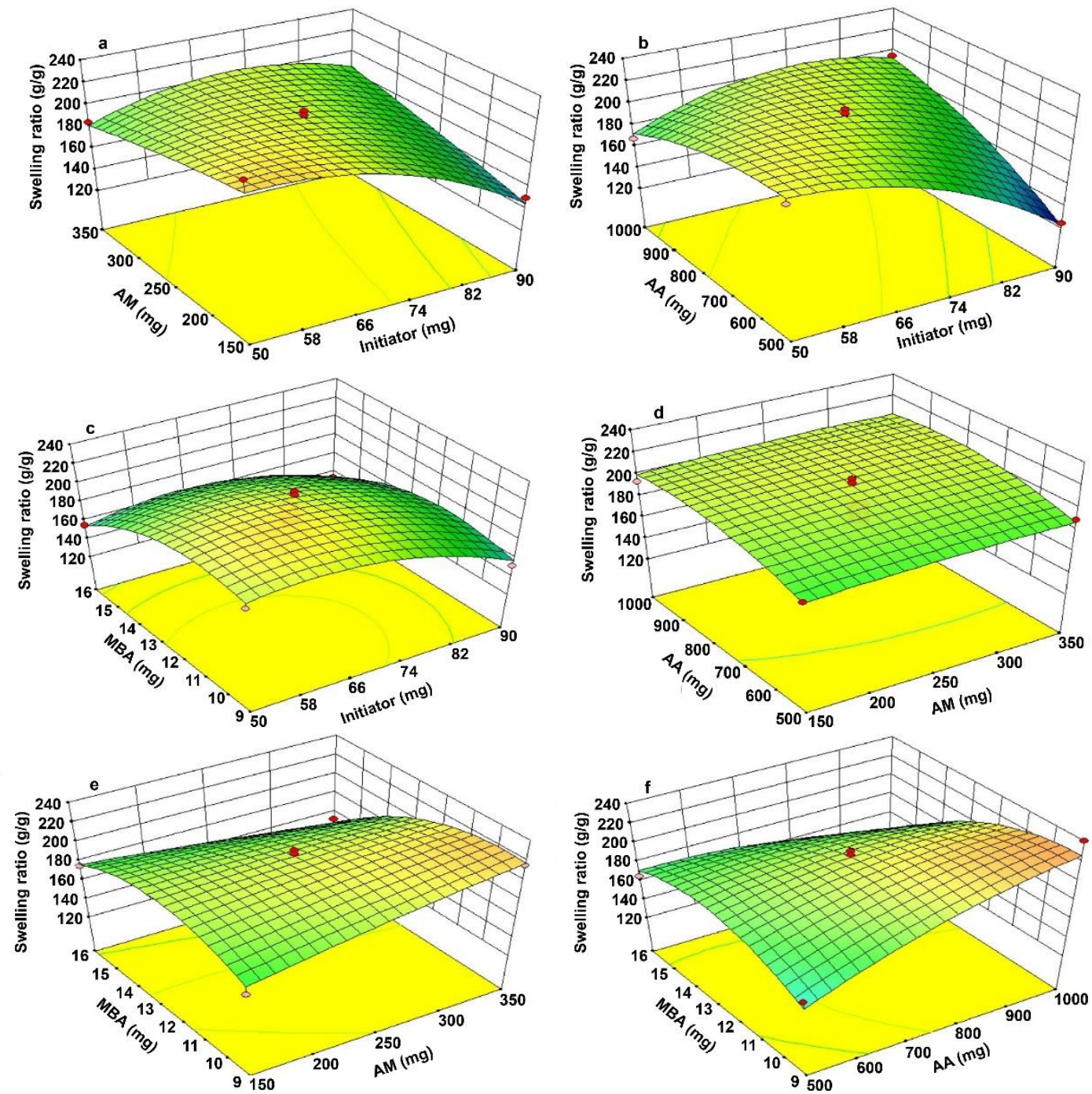

Fig. 2. Response surface graphs of the relationship between swelling ratio and variables: (a) the dosage of initiator and $A M$; (b) the dosage of initiator and AA; (c) the dosage of initiator and MBA; (d) the dosage of $A M$ and $A A ;(e)$ the dosage of AM and MBA; and (f) the dosage of AA and MBA

According to Fig. 2, elevating the dosages of AM and AA increased the swelling ratio of hydrogels, but the degree of influence varied. The dosage of AA had a relatively large impact on the swelling ratio of hydrogels. This large influence mainly because, as the dosage of AA increased, more hydrophilic groups were introduced into the network structure of hydrogels and thus improved the hydrophilicity of the hydrogel (Zhang et al. 2015). Moreover, after washing with sodium hydroxide, $-\mathrm{COOH}$ in the structure of hydrogel was changed to $\mathrm{COO}^{-}$, which could generate higher electrostatic repulsion and expand its network to uptake more water (Du et al. 2016). However, the overdosed AA induced excessive cross-linking and resulted in decreased expansion ability and swelling ratio of the hydrogel (Zhang et al. 2015).

The dosage of the cross-linker (MBA) had great influence on the swelling ratio of the hydrogels. Increasing the dosage of MBA could increase the nodes of network and thus improve the swelling ratio of hydrogels. However, when the amount of the cross-linking agent was too high, the cross-linking degree was excessive, resulting in an extremely condensed network structure. When swelling, it was difficult for the pore size to expand, 
thus making the space for water molecules smaller and decreasing the swelling ratio (Mahdavinia et al. 2004; Pourjavadi et al. 2004).

Based on the results of the Box-Behnken model design, the predicted optimum swelling ratio was $255.7 \mathrm{~g} / \mathrm{g}$ with the preparation conditions as follows: $80.9 \mathrm{mg}$ of initiator, $349.6 \mathrm{mg}$ of AM, $988.7 \mathrm{mg}$ of AA, and $9.39 \mathrm{mg}$ of MBA. To verify the predicted results, the hydrogel was prepared at the above preparation conditions, named Xyl-AMco-AA, and the actual swelling rate was measured as $276.6 \mathrm{~g} / \mathrm{g}$. The experimental values for the welling ratios were close to the predicted values obtained from the fitted model.

\section{FTIR Analysis}

The FTIR spectra of dried CSEL and the as-prepared Xyl-AM-co-AA are shown in Fig. 3. The peaks were assigned on the basis of previous literature (Sun et al. 2001; Wu et al. 2012; Zhang et al. 2015). In the spectrum of dried CSEL, the peak at $3413 \mathrm{~cm}^{-1}$ was related to $-\mathrm{OH}$ in the structure of cellulose-based polysaccharide, hemicellulose-based polysaccharide, and lignin. The stretching vibration of $2931 \mathrm{~cm}^{-1}$ belonged to $\mathrm{C}-\mathrm{H}$ stretching vibration of methyl and methylene. The peaks at 1601,1511 , and $1422 \mathrm{~cm}^{-1}$ were attributed to the stretching vibration of lignin's aromatic ring. The peaks at $1379 \mathrm{~cm}^{-1}$ and $1260 \mathrm{~cm}^{-1}$ corresponded to the $\mathrm{C}-\mathrm{H}$ and $\mathrm{C}-\mathrm{O}$ of the acetyl group, respectively, in the hemicellulose-based polysaccharide. A strong absorption peak emerged at $1051 \mathrm{~cm}^{-1}$, and was assigned to the asymmetric stretching vibration of the glycosidic bond $\mathrm{C}-\mathrm{O}-\mathrm{C}$ in the cellulose-based and hemicellulose-based polysaccharide.

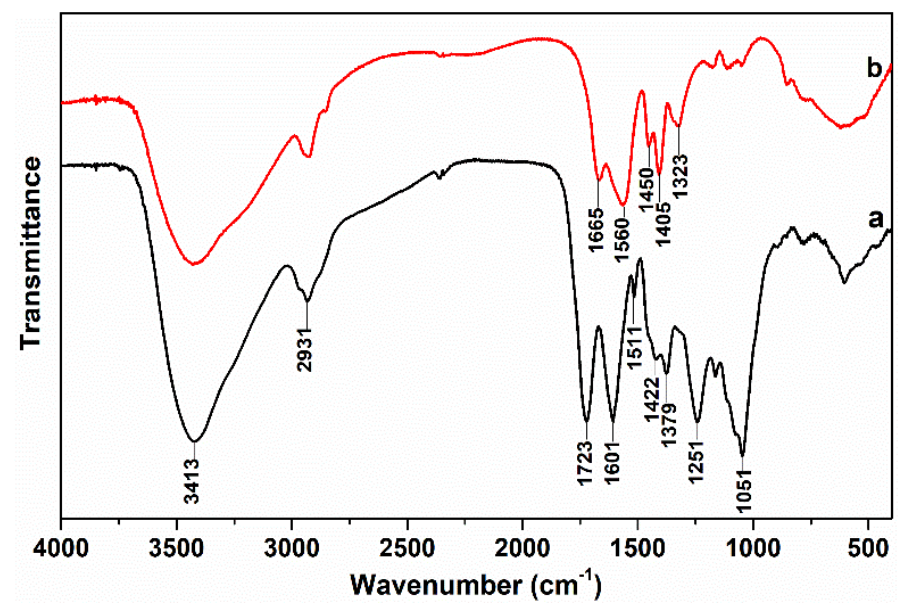

Fig. 3. FTIR spectra of dried CSEL (a) and Xyl-AM-co-AA (b)

Compared with CSEL, the spectrum of Xyl-AM-co-AA was markedly different. Given that AA and AM were added in the prepared process, new peaks emerged at 1665 $\mathrm{cm}^{-1}, 1560 \mathrm{~cm}^{-1}, 1450 \mathrm{~cm}^{-1}, 1405 \mathrm{~cm}^{-1}$, and $1323 \mathrm{~cm}^{-1}$, which were the characteristic absorption peaks of the $\mathrm{C}=\mathrm{O}$ bond of amide $\mathrm{I}$ band, the $\mathrm{N}-\mathrm{H}$ bond of amide II band, the $\mathrm{COO}^{-}$, and the $\mathrm{C}-\mathrm{N}$ bond of amide III band, respectively. From the analysis above, it was concluded that AA and AM were introduced into the structure of produced Xyl-AM-coAA by graft copolymerization, induced by ammonium persulfate and anhydrous sodium sulfite as, respectively, the initiator and MBA as the cross-linker. 


\section{Morphology Analysis of Hydrogels}

The SEM images of as-prepared Xyl-AM-co-AA are shown in Fig. 4, which illustrates that this hydrogel sample had good porous structure. Figures $4 \mathrm{a}, 4 \mathrm{~b}$, and $4 \mathrm{c}$ clearly show that the pore sizes of Xyl-AM-co-AA were different under swelling that occurred at $15{ }^{\circ} \mathrm{C}, 25^{\circ} \mathrm{C}$, and $35^{\circ} \mathrm{C}$. Because of the existence of $-\mathrm{COOH},-\mathrm{OH}$, and $-\mathrm{NH}_{2}$, a good deal of $\mathrm{H}$-bonds formed in the linking structures of Xyl-AM-co-AA. With an increase of swelling temperature, increasing number of these H-bonds would destroyed, followed by formations of hydrophilic residues which could link with $\mathrm{H}_{2} \mathrm{O}$. Therefore, the pore sizes of hydrogels increased. Figures $4 \mathrm{~d}, 4 \mathrm{e}$, and $4 \mathrm{f}$ show the SEM images of XylAM-co-AA swelling at $\mathrm{pH}$ levels of 2, 6, and 11, respectively. The pore size of Xyl-AMco-AA swelling, at $\mathrm{pH}$ of 2 (Fig. 4d), was lower than that of Xyl-AM-co-AA swelling at $\mathrm{pH}$ levels of 6 and 11 (Figs. 4e and 4f). This was probably because the pKa value of the carboxyl group was 4.6. When the $\mathrm{pH}$ value is less than 4.6 , a majority of $\mathrm{COO}^{-}$is protonated into $-\mathrm{COOH}$ (Wu et al. 2012). After swelling in the solution with a $\mathrm{pH}$ of 2 , there was a large amount of $-\mathrm{COOH}$ in the structure of Xyl-AM-co-AA. Hence, a strong hydrogen bonding effect and shrinkage of the pore structure occurred in the hydrogel structure. At higher $\mathrm{pH}$ levels $(\mathrm{pH}>4.6)$, the $-\mathrm{COOH}$ groups were ionized, and the electrostatic repulsion between $\mathrm{COO}^{-}$groups would lead to increased pore size (Yin et al. 2008).
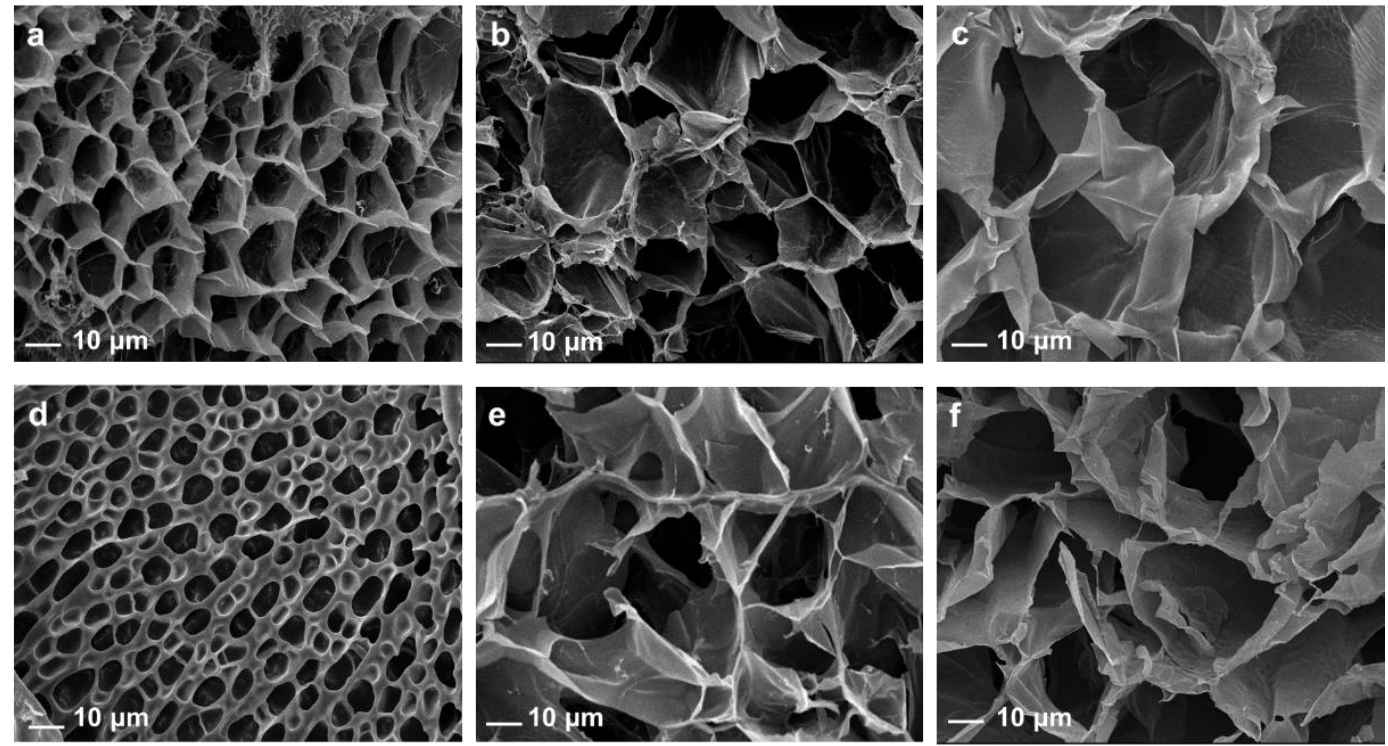

Fig. 4. The SEM images of Xyl-AM-co-AA: (a) swelling at $15^{\circ} \mathrm{C}$; (b) swelling at $25^{\circ} \mathrm{C}$; (c) swelling at $35^{\circ} \mathrm{C}$; (d) swelling at $\mathrm{pH}=2$; (e) swelling at $\mathrm{pH}=6$; and (f) swelling at $\mathrm{pH}=11$

\section{Swelling Degree of Hydrogels}

The adsorption capability of Xyl-AM-co-AA was investigated in solutions with different $\mathrm{pH}$ levels ranging from 2 to 11 , and in water at different temperatures between 5 and $35^{\circ} \mathrm{C}$, as shown in Fig. 5. Figure 5a shows that the swelling ratio of Xyl-AM-co-AA considerably increased when the $\mathrm{pH}$ increased from 2 to 4 , and it slowly increased when the $\mathrm{pH}$ increased from 4 to 6 . The swelling ratio decreased in the $\mathrm{pH}$ range of 9 to11. As the $\mathrm{pH}$ value increased from 2 to 11 , more $-\mathrm{COOH}$ groups in Xyl-AM-co-AA were ionized into $\mathrm{COO}^{-}$groups. The electrostatic repulsion forces between $\mathrm{COO}^{-}$groups were strengthened, and the networks of Xyl-AM-co-AA were expanded with the greater increase

Wang et al. (2020). "Hydrogels from poplar xylan," BioResources 15(2), 2525-2539. 
in $\mathrm{pH}$, thus leading to the high swelling ratio (Cao et al. 2014). However, it was observed that in the solutions with $\mathrm{pH}$ levels of 9 and 11, the equilibrium swelling ratio decreased from $276.7 \mathrm{~g} / \mathrm{g}(\mathrm{pH}=6)$ to $270.2 \mathrm{~g} / \mathrm{g}$ and $247.9 \mathrm{~g} / \mathrm{g}$, respectively. This result was associated with the presence of a large number of metal ions in the alkaline solutions, resulting in electrostatic screening. In these cases, the electrostatic repulsion forces between $\mathrm{COO}^{-}$ groups was weakened, which could reduce the network expansion capability of Xyl-AMco-AA. As a result, the swelling ratio decreased (Lee and Wu 1996; Yin et al. 2008). Most notably, a low swelling ratio of $2.2 \mathrm{~g} / \mathrm{g}$ emerged at a $\mathrm{pH}$ of 2 . This ratio was closely related to the fact that, at highly acidic conditions $(\mathrm{pH}=2)$, most of $\mathrm{COO}^{-}$was protonated into $\mathrm{COOH}$, which strengthened the H-bond effect and led to a shrinkage of the pore structure of this hydrogel. A low swelling ratio resulted.

From Fig. 5b, the swelling ratios of 197.3, 206.7, 276.6, and $282.1 \mathrm{~g} / \mathrm{g}$ were obtained at the temperatures of $5,15,25$, and $35{ }^{\circ} \mathrm{C}$, respectively. This range illustrated that the swelling ratio of Xyl-AM-co-AA increased with the increasing temperatures. The swelling ratio at $35^{\circ} \mathrm{C}$ was the highest $(292.1 \mathrm{~g} / \mathrm{g})$. Because hydrophilic AM and AA were introduced into the hydrogels network, the contents of the hydrophilic groups in the hydrogel network increased, forming more H-bonds in the linking structure of hydrogel, and requiring more energy to break the H-bonds (Wang et al. 2013; Wang et al. 2019). It was possible that the increasing temperature broke an increasing number of $\mathrm{H}$-bonds in the linking structure of hydrogel, and then hydrophilic residues produced a link with $\mathrm{H}_{2} \mathrm{O}$, thus increasing the swelling ratio (Kipcak et al. 2014). Moreover, the rise in temperature could have resulted in thermal mobility of the polymer molecules inside the hydrogels, and then the swelling ratio increased (Rodriguez et al. 2006; Kipcak et al. 2014).
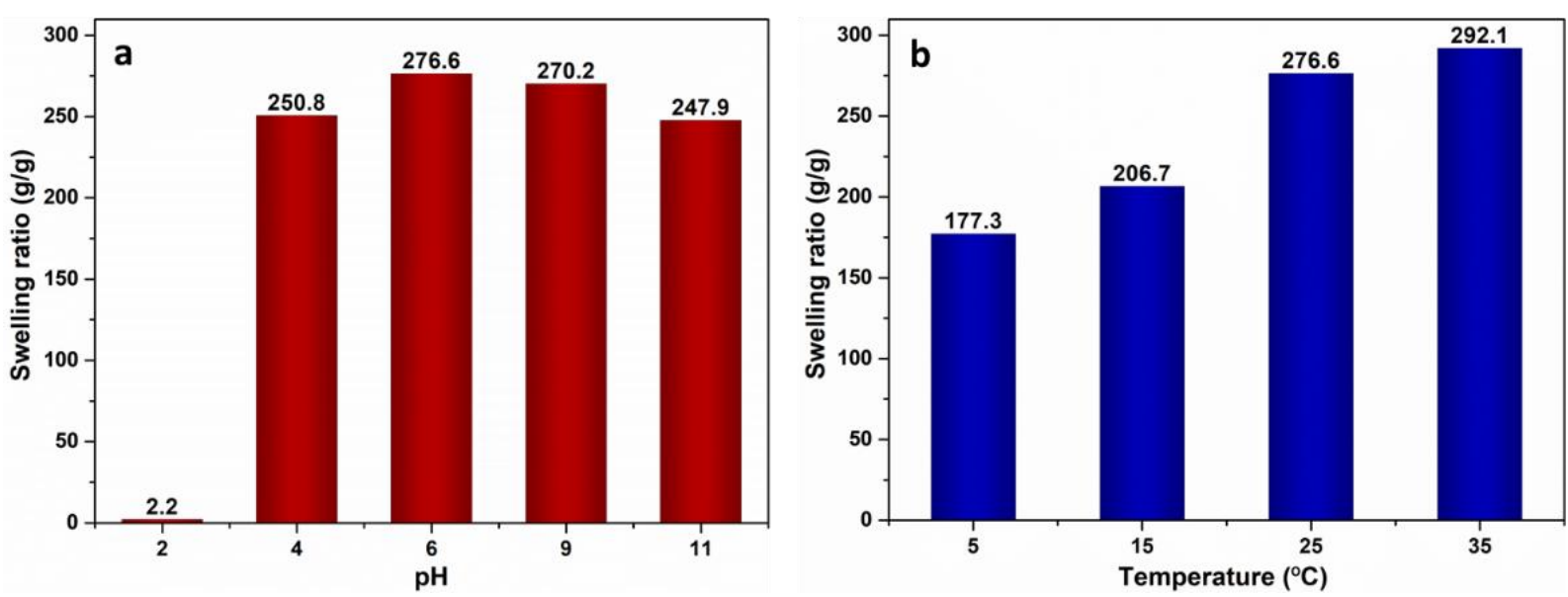

Fig. 5. The swelling ratios of Xyl-AM-co-AA in solutions with $\mathrm{pH}$ levels of 2, 4, 6, 9, and 11 (a), and in water at temperatures of $5,15,25$, and $35^{\circ} \mathrm{C}(\mathrm{b})$

\section{CONCLUSIONS}

1. To obtain hydrogels with high levels of swelling, RSM coupled with Box-Behnken design was used to optimize the swelling ratio of hydrogels. It was found that the predicted value $(255.7 \mathrm{~g} / \mathrm{g})$ was close to the experimental value $(276.6 \mathrm{~g} / \mathrm{g})$. Meanwhile, the optimum preparation conditions were obtained as follows: $80.9 \mathrm{mg}$ of initiator, $349.6 \mathrm{mg}$ of AM, $988.7 \mathrm{mg}$ of AA, and $9.39 \mathrm{mg}$ of MBA.

Wang et al. (2020). "Hydrogels from poplar xylan," BioResources 15(2), 2525-2539. 
2. The electrostatic repulsion forces between $\mathrm{COO}^{-}$groups were an important factor in determining the swelling ratio and the pore size of the hydrogel. As the $\mathrm{pH}$ value changed, the degree of ionization of $-\mathrm{COOH}$ varied, further obtaining electrostatic repulsion with differing strengths, and thus resulting in different swelling ratios and pore sizes.

3. H-bonds played an important role in pore sizes. When temperature increased, an increasing number of $\mathrm{H}$-bonds were broken. Thus, the swelling ratio of Xyl-AM-coAA were also related to temperature.

\section{ACKNOWLEDGMENTS}

This work was financially supported by the National Key Research and Development Plan (Grant No. 2017YFB0307901).

\section{ABBREVIATIONS}

\section{Full Name}

Concentrated Steam Explosion Liquid

Acrylic Acid

Acrylamide

N,N'-methylenebisacrylamide

Response Surface Methodology

Xylan-based Polysaccharides

National Renewable Energy Laboratory

Glucose-based Polysaccharide

Arabinose-based Polysaccharide

\section{Abbreviation}

CSEL

AA

$\mathrm{AM}$

MBA

RSM

Xyl-P

NREL

Glu-P

Arab-P

\section{REFERENCES CITED}

Ahmed, E. M. (2015). "Hydrogel: Preparation, characterization, and applications: A review," Journal of Advanced Research 6(2), 105-121. DOI: 10.1016/j.jare.2013.07.006

Al-Rudainy, B., Galbe, M., Arcos Hernandez, M., Jannasch, P., and Wallberg, O. (2019). "Impact of lignin content on the properties of hemicellulose hydrogels," Polymers 11(1), Article Number 35. DOI: 10.3390/polym11010035

Asfaram, A., Ghaedi, M., Azqhandi, M. H. A., Goudarzi, A., and Dastkhoon, M. (2016). "Statistical experimental design, least squares-support vector machine (LS-SVM) and artificial neural network (ANN) methods for modeling the facilitated adsorption of methylene blue dye," RSC Advances 6(46), 40502-40516. DOI: 10.1039/C6RA01874B 
Bao, Y., Ma, J., and Li, N. (2011). "Synthesis and swelling behaviors of sodium carboxymethyl cellulose-g-poly(AA-co-AM-co-AMPS)/MMT superabsorbent hydrogel," Carbohydrate Polymers 84(1), 76-82. DOI: 10.1016/j.carbpol.2010.10.061

Cao, X., Peng, X., Zhong, L., and Sun, R. (2014). "Multiresponsive hydrogels based on xylan-type hemicelluloses and photoisomerized azobenzene copolymer as drug delivery carrier," Journal of Agricultural and Food Chemistry 62(41), 10000-10007. DOI: $10.1021 / \mathrm{jf504040s}$

Dai, Q. Q., Ren, J. L., Peng, F., Chen, X. F., Gao, C. D., and Sun, R. C. (2016). "Synthesis of acylated xylan-based magnetic $\mathrm{Fe}_{3} \mathrm{O}_{4}$ hydrogels and their application for $\mathrm{H}_{2} \mathrm{O}_{2}$ detection," Materials 9(8), Article Number 690. DOI: 10.3390/ma9080690

Dil, E. A., Ghaedi, M., Ghaedi, A. M., Asfaram, A., Goudarzi, A., Hajati, S., Soylak, M., Agarwal, S., and Gupta, V. K. (2016). "Modeling of quaternary dyes adsorption onto ZnO-NR-AC artificial neural network: Analysis by derivative spectrophotometry," Journal of Industrial and Engineering Chemistry 34, 186-197. DOI: 10.1016/j.jiec.2015.11.010

Du, J., Li, B., Li, C., Zhang, Y., Yu, G., Wang, H., and Mu, X. (2016). "Tough and multiresponsive hydrogel based on the hemicellulose from the spent liquor of viscose process," International Journal of Biological Macromolecules 88, 451-456. DOI: 10.1016/j.ijbiomac.2016.04.013

Kabiri, K., Omidian, H., Zohuriaan-Mehr, M. J., and Doroudiani, S. (2011). "Superabsorbent hydrogel composites and nanocomposites: A review," Polymer Composites 32(2), 277-289. DOI: 10.1002/pc.21046

Kipcak, A. S., Ismail, O., Doymaz, I., and Piskin, S. (2014). "Modeling and investigation of the swelling kinetics of acrylamide-sodium acrylate hydrogel," Journal of Chemistry 2014, Article ID 281063. DOI: 10.1155/2014/281063

Lee, W. F., and Wu, R. J. (1996). "Superabsorbent polymeric materials. I. Swelling behaviors of crosslinked poly(sodium acrylate-co-hydroxyethyl methacrylate) in aqueous salt solution," Journal of Applied Plymer Science 62(7), 1099-1114. DOI: 10.1002/(SICI)1097-4628(19961114)62:7<1099::AID-APP16>3.0.CO;2-1

Li, X., and Pan, X. (2010). "Hydrogels based on hemicellulose and lignin from lignocellulose biorefinery: A mini-review," Journal of Biobased Materials and Bioenergy 4(4), 289-297. DOI: 10.1166/jbmb.2010.1107

Liu, X., Luan, S., and Li, W. (2019). "Utilization of waste hemicelluloses lye for superabsorbent hydrogel synthesis," International Journal of Biological Macromolecules 132, 954-962. DOI: 10.1016/j.ijbiomac.2019.04.041

Mahdavinia, G. R., Pourjavadi, A., Hosseinzadeh, H., and Zohuriaan, M. J. (2004). "Modified chitosan 4. Superabsorbent hydrogels from poly(acrylic acid-coacrylamide) grafted chitosan with salt-and $\mathrm{pH}$-responsiveness properties," European Polymer Journal 40(7), 1399-1407. DOI: 10.1016/j.eurpolymj.2004.01.039

Marandi, G. B., Esfandiari, K., Biranvand, F., Babapour, M., Sadeh, S., and Mahdavinia, G. R. (2008). "PH sensitivity and swelling behavior of partially hydrolyzed formaldehyde-crosslinked poly(acrylamide) superabsorbent hydrogels," Jouranl of Applied Polymer Science 109(2), 1083-1092. DOI: 10.1002/app.28205

Peng, X. W., Ren, J. L., Zhong, L. X., Peng, F., and Sun, R. C. (2011). "Xylan-rich hemicelluloses-graft-acrylic acid ionic hydrogels with rapid responses to $\mathrm{pH}$, salt, and organic solvents," Journal of Agricultural and Food Chemistry 59(15), 8208-8215. DOI: $10.1021 /$ jf201589y 
Pourjavadi, A., Harzandi, A. M., and Hosseinzadeh, H. (2004). "Modified carrageenan 3. Synthesis of a novel polysaccharide-based superabsorbent hydrogel via graft copolymerization of acrylic acid onto kappa-carrageenan in air," European Polymer Journal 40(7), 1363-1370. DOI: 10.1016/j.eurpolymj.2004.02.016

Qiu, Y., and Park, K. (2001). "Environment-sensitive hydrogels for drug delivery," Advanced Drug Delivery Reviews 53(3), 321-339. DOI: 10.1016/S0169409X(01)00203-4

Risbud, M. V., Hardikar, A. A., Bhat, S. V., and Bhonde, R. R. (2000). "PH-sensitive freeze-dried chitosan-polyvinyl pyrrolidone hydrogels as controlled release system for antibiotic delivery," Journal of Controlled Release 68(1), 23-30. DOI: 10.1016/S0168-3659(00)00208-X

Rodriguez, D. E., Romero-García, J., Ramírez-Vargas, E., Ledezma-Pérez, A., and AríasMarín, E. (2006). "Synthesis and swelling characteristics of semi-interpenetrating polymer network hydrogels composed of poly(acrylamide) and poly $(\gamma$-glutamic acid)," Materials Letters 60(11), 1390-1393. DOI: 10.1016/j.matlet.2005.11.033

Ruiz, E., Cara, C., Manzanares, P., Ballesteros, M., and Castro, E. (2008). "Evaluation of steam explosion pre-treatment for enzymatic hydrolysis of sunflower stalks," Enzyme and Microbial Technology 42(2), 160-166. DOI: 10.1016/j.enzmictec.2007.09.002

Sluiter, A., Hames, B., Ruiz, R., Scarlata, C., Sluiter, J., and Templeton, D. (2006). Determination of Sugars, Byproducts, and Degradation Products in Liquid Fraction Process Samples (NREL/TP-510-42623), National Renewable Energy Laboratory, Golden, CO, USA.

Sun, R., Tomkinson, J., Mao, F. C., and Sun, X. F. (2001). "Physicochemical characterization of lignins from rice straw by hydrogen peroxide treatment," Journal of Applied Polymer Science 79(4), 719-732. DOI: 10.1002/10974628(20010124)79:4<719::AID-APP170>3.0.CO;2-3

Sun, X. F., Wang, H. H., Jing, Z. X., and Mohanathas, R. (2013). "Hemicellulose-based pH-sensitive and biodegradable hydrogel for controlled drug delivery," Carbohydrate Polymers 92(2), 1357-1366. DOI: 10.1016/j.carbpol.2012.10.032

Wang, Q., Wilfong, W. C., Kail, B. W., Yu, Y., and Gray, M. L. (2017). "Novel polyethylenimine-acrylamide/ $\mathrm{SiO}_{2}$ hybrid hydrogel sorbent for rare-earth-element recycling from aqueous sources," ACS Sustainable Chemical Engineering 5(11), 10947-10958. DOI: 10.1021/acssuschemeng.7b02851

Wang, S. Y., Li, H. L., Ren, J. L., Liu, C. F., Peng, F., and Sun, R. C. (2013). "Preparation of xylan citrate - A potential adsorbent for industrial wastewater treatment," Carbohydrate Polymers 92(2), 1960-1965. DOI: 10.1016/j.carbpol.2012.11.079

Wang, X., Dai, Q., Zhong, H., Liu, X., and Ren, J. (2019). "Fast-responsive temperaturesensitive hydrogels," BioResources 14(4), 8543-8558. DOI: 10.15376/biores.14.4.8543-8558

Wu, F., Zhang, Y., Liu, L., and Yao, J. (2012). "Synthesis and characterization of a novel cellulose-g-poly(acrylic acid-co-acrylamide) superabsorbent composite based on flax yarn waste," Carbohydrate Polymers 87(4), 2519-2525. DOI: 10.1016/j.carbpol.2011.11.028

Yang, J. Y., Zhou, X. S., and Fang, J. (2011). "Synthesis and characterization of temperature sensitive hemicellulose-based hydrogels," Carbohydrate Polymers 86(3), 1113-1117. DOI: 10.1016/j.carbpol.2011.05.043 
Yashin, V. V., and Balazs, A. C. (2006). "Pattern formation and shape changes in selfoscillating polymer gels," Science 314(5800), 798-801. DOI: 10.1126/science. 1132412

Yin, Y., Ji, X., Dong, H., Ying, Y., and Zheng, H. (2008). "Study of the swelling dynamics with overshooting effect of hydrogels based on sodium alginate- $g$-acrylic acid," Carbohydrate Polymers 71(4), 682-689. DOI: 10.1016/j.carbpol.2007.07.012

Zhang, J., Xiao, H., Li, N., Ping, Q., and Zhang, Y. (2015). "Synthesis and characterization of super-absorbent hydrogels based on hemicellulose," Journal of Applied Polymer Science 132(34), 42441-42446. DOI: 10.1002/app.42441

Zhang, X. Z., Wu, D. Q., and Chu, C. C. (2004). "Synthesis, characterization and controlled drug release of thermosensitive IPN-PNIPAAm hydrogels," Biomaterials 25(17), 3793-3805. DOI: 10.1016/j.biomaterials.2003.10.065

Zhao, W., Glavas, L., Odelius, K., Edlund, U., and Albertsson, A. C. (2014). “A robust pathway to electrically conductive hemicellulose hydrogels with high and controllable swelling behavior," Polymer 55(13), 2967-2976. DOI:

10.1016/j.polymer.2014.05.003

Article submitted: November 4, 2019; Peer review completed: January 27, 2020;

Revisions accepted: February 7, 2020; Published: February 20, 2020.

DOI: $10.15376 /$ biores.15.2.2525-2539 